\title{
Etnobotânica das variedades locais do cará (Dioscorea spp.) cultivados em comunidades no município de Caapiranga, estado do Amazonas
}

Albejamere Pereira de Castro ${ }^{1,3}$, Therezinha de Jesus Pinto Fraxe ${ }^{1}$, Henrique dos Santos Pereira ${ }^{1}$ e Valdely Ferreira Kinupp ${ }^{2}$

Recebido em 9/11/2011. Aceito em 6/06/2012

\begin{abstract}
RESUMO
(Etnobotânica das variedades locais do cará (Dioscorea spp.) cultivados em comunidades no município de Caapiranga, estado do Amazonas). Este estudo trata da investigação das práticas de conservação da agrodiversidade do cará (Dioscorea spp.) mantidas por comunidades produtoras no município de Caapiranga, Amazonas, usando ferramentas metodológicas da etnobotânica, em busca de associar o saber científico com o conhecimento perceptivo e cultural dos agricultores locais sobre a cultura do cará. Foi empregado o método das quatro-células, levantamento e coletas botânicas, aplicação de formulário, entrevistas, observação participativa com os agricultores sobre as peculiaridades de cada espécie e variedades locais. Os materiais coletados foram identificados por especialista do Herbário do Instituto Federal de Educação Ciência, e Tecnologia do Amazonas (EAFM) e do Instituto de Botânica-IBt, São Paulo e acondicionados no Herbário da Universidade Federal do Amazonas (HUAM), além de serem multiplicadas no campo de produção vegetal da UFAM, para posterior identificação das demais espécies e/ou variedades não identificadas. Dentre as 15 variedades locais pesquisadas, 10 pertencem à espécie $D$. trifida, uma à $D$. bulbifera. Quanto às quatro restantes, por não serem mais cultivadas nas roças, não foi possível sua identificação botânica. Verificou-se que os agricultores tradicionais pesquisados possuem grande conhecimento sobre as roças, bem como sobre as variedades locais cultivadas, e possuem formas de manejo e conservação que são fundamentais para a manutenção da agrodiversidade das suas roças. Os sistemas produtivos de Caapiranga constituem verdadeiras coleções de germoplasma de cará e representam a principal estratégia local de conservação in situ/on farm do recurso genético e, portanto, devem ser mantidos e incentivados.
\end{abstract}

Palavras-chave: etnovariedades, propagação, variabilidade

\begin{abstract}
(Ethnobotany of local varieties of yams (Dioscorea spp.) cultivated in the municipality of Caapiranga, AM ). This study employed methodological tools of ethnobotany to better understand agrobiodiversity conservation practices used for yams (Dioscorea spp.) cultivated by farming communities in the municipality of Caapiranga (Amazonas State. For this work, a four-celled method, botanical inventory and collecting, a form, interviews and participant observation with farmers about the peculiarities of each species and varieties were used. The collected material was identified by an expert at the Herbarium of the Federal Institute of Education, Science and Technology of Amazonas (EAFM) and the Institute of Botany, IBt, São Paulo, and deposited in the Herbarium of Federal University of Amazonas (HUAM). For further identification of all collected species and varieties, the collected material was grown in a UFAM experimental field. Among the fifteen local varieties surveyed, ten are believed to belong to $D$. trifida and one to D. bulbifera. It was not possible to identify the four other taxa because they are no longer cultivated in gardens. It was found that the traditional farmers surveyed have great knowledge about the cultivated fields, as well as about cultivated local varieties, and that they have different forms of management and conservation that are fundamental to the maintenance of the agrobiodiversity of their gardens. The production systems of Caapiranga are true germplasm collections and the major local strategy for in situ/on farm conservation of genetic resources, and, therefore, should be maintained and encouraged.
\end{abstract}

Key-words: landraces, propagation, variability

\footnotetext{
${ }^{1}$ Universidade Federal do Amazonas, Campus Universitário Aleixo, Manaus, AM, Brasil

${ }^{2}$ Instituto Federal do Amazonas, São José Operário, AM, Brasil

${ }^{3}$ Autor para correspondência: albejamere@yahoo.com.br
} 


\section{Introdução}

A família Dioscoreaceae foi reconhecida, inicialmente, por Brown em 1819 com o nome Dioscoreae (Burkill 1967 apud Carvalho, Texeira \& Borges 2009). Atualmente são reconhecidos mundialmente, aproximadamente, oito gêneros, com cerca de 850 espécies, sendo $95 \%$ pertencente ao gênero Dioscorea (Marbberley 2008). De acordo com Cagnon et al. (2002), esta família possui representantes no mundo inteiro e, ainda se discute a sua origem e distribuição.

As espécies Dioscorea alata L. e D. esculenta (Lour) Burkill são originárias da Índia Central, enquanto D. hispida Dennst, D.pentaphylla L. e D. bulbifera L. tiveram a região Indo-Malaia como local de origem. São originárias da África D. dumentorum (Kaunth) Pax., D. cayenensis Lam., D. rotundata Poir. Já a D. trifida L.f. teria seu centro de origem na América Central e Sul (Abramo 1990; Cagnon et al. 2002; Carvalho, Teixeira \& Borges 2009). Entretanto, Cáuper (2006, p.38) relata que a origem e distribuição geográfica de D. trifida é a Amazônia. Kirizawa et al. (2010) estimam que ocorram, no Brasil, 130 espécies de Dioscorea, único gênero da família presente em todas as regiões do país. Pedralli (1988) relata que a maioria das espécies ainda hoje é pouco estudada. Embora seja elevado o número de espécies, apenas 90 espécies de regiões tropicais servem para alimentação humana (Montaldo 1991).

Segundo Santos (2002), a cultura do cará (Dioscorea spp.) apresenta grande importância socioeconômica para a região Nordeste do Brasil, sobretudo para os Estados da Paraíba, Pernambuco, Alagoas, Bahia e Maranhão, por constituir um negócio agrícola muito promissor dado a excelente qualidade nutritiva e energética de suas túberas e a grande utilidade para a alimentação humana. Como alimento, o cará é rico em diversas vitaminas do complexo B (tiamina, riboflavina, niacina), além das vitaminas A, vitamina $\mathrm{C}$ (ácido ascórbico) e carboidratos, principalmente, em amido, o qual é a principal reserva energética dos vegetais, como também, a principal fonte de carboidratos na dieta humana, além de apreciáveis teores de proteína e de gordura (Oliveira et al. 2007).

O cará representa grande importância na segurança alimentar por possuir características nutricionais excelentes e ser promissora pela sua produtividade resultante da alta adaptabilidade as condições edafoclimáticas das regiões brasileiras. Entretanto, a maioria das espécies, ainda hoje, é pouco estudada, principalmente a $D$. trifida em relação às outras espécies de Dioscorea comestíveis (Pedralli 1998 e Ramos-Escudero et al. 2010). De acordo com Castro (2011), a principal espécie cultivada no Amazonas é D. trifida, 48\% do cará comercializado na capital provêm do município de Caapiranga. Além desta constatação, o município possui em seu calendário de eventos culturais a "Festa do Cará". Nesse sentido é possível constatar que o município se destaca como o maior produtor de cará no Estado do Amazonas e que, possivelmente, pode ser possuidor de uma elevada agrodi- versidade relacionada a esta cultura. Diante deste contexto, este artigo tem por finalidade revelar a agrodiversidade e as formas de conservação do cará (Dioscorea spp.) em comunidades produtoras, no município de Caapiranga, Amazonas, utilizando-se ferramentas da etnobotânica, em busca de resgatar o conhecimento perceptivo e cultural dos agricultores sobre a cultura do cará, estas práticas locais servirão como alternativa de conservação dos recursos fitogenéticos relacionados à cultura do cará, e servirão como ferramenta para implementação de políticas de conservação, visando à permanência de uma diversidade, tanto cultural quanto biológica no meio agrícola amazônico.

\section{Materiais e métodos}

\section{Área de estudo}

O estudo foi realizado nas comunidades - Patauá, Monte Alegre, Maloca e Vila Nova no município de Caapiranga, Amazonas (Fig. 1). Caapiranga localiza-se na margem esquerda do Baixo rio Solimões, dista da capital do estado $147 \mathrm{~km}$. O município está assentado em uma área de terra-firme, sua área territorial é de $9.617 \mathrm{Km}^{2}$, clima tropical chuvoso e úmido, com temperatura média de $27^{\circ} \mathrm{C}$. Possui solo arenoso com bom índice de permeabilidade e floresta densa tropical.

O município de Caapiranga possui atualmente 45 comunidades, entretanto as que se destacam na produção de cará são: Patauá, Monte Alegre, Vila Nova e Maloca; as quais são constituídas pelos seguintes números de famílias 15, 18, 33 e 80 , respectivamente (Castro 2011). Devido à proximidade das comunidades citadas uma das outras, os agricultores possuem peculiaridades socioeconômicas e culturais parecidas, como por exemplo, exercem uma pluralidade de atividades (caça, pesca, extrativismo vegetal e agricultura) que são fundamentais para complementar seus rendimentos e suas necessidades de sobrevivência, exceto a comunidade Patauá, Monte Alegre e Maloca que além das atividades já citadas realizam a piscicultura e apicultura. Na atividade agrícola, o cultivo do cará ocupa lugar de destaque para sobrevivência destas famílias. O cultivo do cará, denominado pela população de carazal, é uma tradição antiga, que é passada de pai para filho nestas comunidades. De acordo com a população pesquisada o cará já era cultivado pelos índios que habitavam aquela região os Ticunas e Muras. Nesse sentido todo o meio de produção desta cultura é de forma rudimentar itinerante com "corte e queima" sem o uso de insumos ou mecanismo convencionais, exceto o facão e a enxada.

\section{Métodos e técnicas de abordagem}

O método utilizado foi a análise participativa de quatro-células visando identificar os recursos biológicos que têm papel importante na segurança alimentar (Rana \& Sthapit 2007). Este facilitou uma análise sistemática da extensão e 


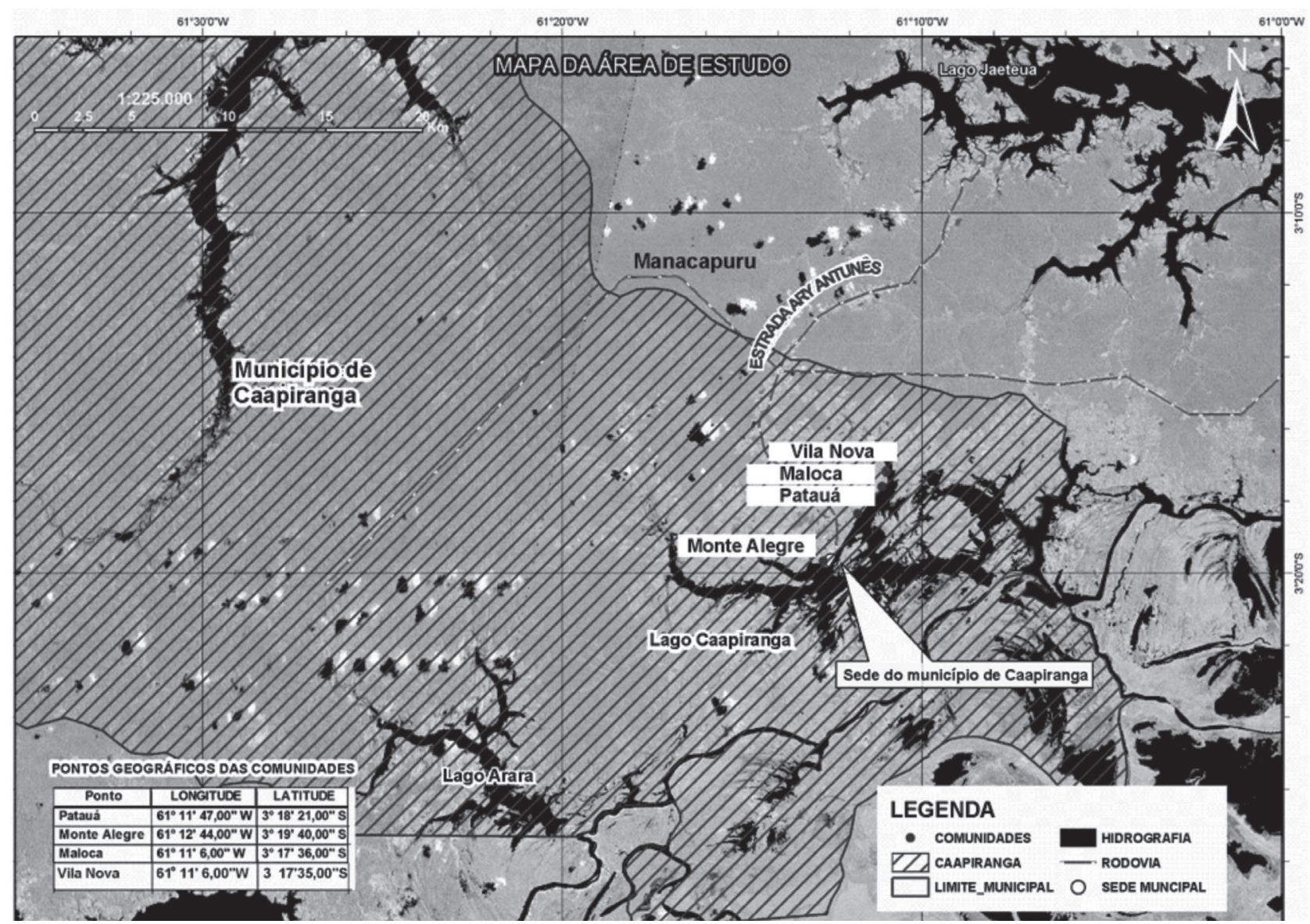

Figura 1. Mapa das comunidades que se destacam na produção de cará, município de Caapiranga, margem esquerda do Baixo rio Solimões, Amazonas. Fonte: Base Cartográfica disponibilizada pelo Instituto de Proteção Ambiental do Amazonas - IPAAM, imagem Landsat 5TM na composição 5R4G3B, 2009.

da distribuição da diversidade dos cultivos locais de cará dos agricultores possibilitando junto com a etnobotânica, identificar as variedades locais de características únicas, as raras e as comuns nas roças dos agricultores.

Inicialmente foram contatados os presidentes de cada comunidade, os quais indicaram os agricultores que a mais tempo se dedicam ao cultivo do cará na região. Em seguida foi realizada uma reunião para expor aos participantes da pesquisa a natureza do trabalho, esta se repetiu outras vezes durante a pesquisa. Em uma das reuniões nas escolas das comunidades pesquisadas foram desenhadas no quadro branco, as quatro-células conforme o método descrito por Rana e Sthapit (2007, p.162), onde foram colocadas as principais variedades locais de cará mais citadas pelos agricultores, tamanho aproximado das áreas de cultivo, número de família e o tipo de intercâmbio de semente entre os agricultores. Além deste método, foram aplicados formulários e entrevistas.

O formulário teve como objetivo, levantar dados sobre as variedades locais, tais como: nomes dados pelos agricultores, dados etnobotânicos, etnofenologia, manutenção nas roças, utilidades na alimentação, comercialização. O tipo de formulário que foi aplicado se constitui da combinação de perguntas abertas e fechadas, este foi aplicado ao chefe de família ou responsável pela propriedade. A intensidade amostral de famílias pesquisadas foram de 15 para cada comunidade que corresponde a $20 \%$ da Maloca, $50 \%$ da Vila Nova, $83 \%$ do Monte Alegre e 20\% do Patauá referente do total de residência de cada comunidade pesquisada. Para a validação do formulário familiar foi utilizado também o formulário focal.

O formulário focal foi utilizado para coletar informações em grupos (em reuniões com os comunitários) e, consequentemente, foram comparadas e/ou combinadas com os elementos dos formulários familiar e das entrevistas individuais, o qual proporcionou um aprendizado das experiências e perspectivas dos participantes, permitindo a coleta de dados através da interação grupal.

Outra ferramenta que contribuiu eficazmente para a realização desta pesquisa foi a entrevista, que ocorreu de duas formas: semiestruturadas e não estruturada e teve, como finalidade, apreender e entender o conhecimento dos agricultores referentes à descrição das variedades locais, ou seja como eles distinguiam uma variedade de outra, e qual o seu conhecimento sobre a fenologia da planta, hábito alimentar referente ao uso da planta. Além de envolver informações a 
respeito do conhecimento da relação homem, planta e ambiente, obtido através do cotidiano e transmitido através de gerações. Nesta técnica de abordagem, foi utilizado gravador com a devida autorização dos participantes e diário de campo.

Para identificação e averiguação da fenologia do cará foram feitas coletas de variedade de cará para a formação de uma coleção de variedades locais (11 variedades com 10 repetições em cada bloco) de cará na Área de Produção Vegetal da Universidade Federal do Amazonas, as observações foram realizadas diariamente. Nas coletas botânicas para identificação, após a herborização, os vegetais foram depositados com as seguintes numerações $(8584,8586$, 8587, 8588, 8589, 8590, 8591, 8592 e 8594) no Herbário da Universidade Federal do Amazonas (HUAM). Entretanto, sua identificação foi realizada no Herbário do Instituto Federal de Educação, Ciência e Tecnologia do Amazonas (EAFM) e no Instituto de Botânica-IBt, São Paulo-SP. É importante ressaltar que este trabalho para ser realizado foi submetido e aprovado pelo Comitê de Ética e Pesquisa da Universidade Federal do Amazonas (CEP/UFAM) e tem como número do protocolo CAAE-0316.0.115.000-09.

\section{Resultados e discussão}

\section{Fases de desenvolvimento do cará (Dioscorea trifida L.f.)}

Os agricultores de Caapiranga desenvolveram "calendários mentais", segundo os quais são planejadas as atividades para o plantio do cará. Neste planejamento são definidos quando e quanto será plantado, o tamanho da área a ser ocupada, as variedades, entre outras decisões. Tais decisões são tomadas em acordo com a sazonalidade climática e a fenologia da planta, a partir da percepção e do conhecimento adquirido através do cotidiano e manejo do vegetal. Um exemplo disto é a decisão sobre o momento em que deve ser iniciada a limpeza da área para o próximo cultivo do cará. Cerca de $80 \%$ dos agricultores relataram que escolhem e iniciam a limpeza da área no término da floração, marcada pelo início do secamento das flores do cará, sete meses, após o plantio. Durante o ciclo de crescimento da cultura do cará observaram-se cinco fases distintas, que podem variar em função das condições de cultivo, espécie e genótipo:

a) Fase de dormência

A qualidade do material de plantio depende da forma como este material foi manuseado durante o seu período de dormência que, de acordo com dos dados coletados, varia de 40 a 80 dias após a colheita, quando o tubérculo é colhido com nove meses de idade. Uma técnica adotada pelos agricultores para prolongar a dormência dos tubérculos é a retirada dos brotos que surgem na epiderme dos tubérculos. Isto geralmente é realizado para atrasar o plantio por 10 a 20 dias.

A forma de conservação utilizada pelos agricultores para garantir a viabilidade dos tubérculos-sementes é a de levar estes para ambientes secos, arejados, na sombra, os quais podem ser a casa de farinha ou um barraco construído na lateral das áreas da roça. Porém, os ambientes mais utilizados são as capoeiras ou florestas próximas das áreas onde será o novo plantio. Nestes locais, os tubérculos ficam cobertos por folhas de bananeira ou palha, o que confere boas condições de acondicionamento por pouco tempo. Em épocas de temperaturas elevadas, é necessário que o plantio seja mais rápido. Estes locais (capoeira e floresta) são mais utilizados por reduzir o custo e o trabalho com o transporte do material de plantio (Fig. 2).

De acordo com os agricultores, o tubérculo só está maduro quando a ponta da área distal indica alterações na cor, que vai do claro ao escuro, e produz uma camada de tegumento (casca) mais grossa e suberizada. Os tubérculos colhidos frescos com a ponta da área distal de cor clara (Fig. 3) não podem brotar, estão na fase de dormência que pode durar até 80 dias, dependendo da idade em que foi colhido. Segundo os dados relatados e observados, o aparecimento de pequenas protuberâncias sob a camada da epiderme do tubérculo é uma indicação do fim da dormência e início da brotação.

\section{b) Fase vegetativa}

Inicia após a brotação com o surgimento das primeiras folhas, até a formação dos ramos primários e secundários. Esta fase ocorre de aproximadamente 80 a 150 dias, após o plantio (Tabela 1). É caracterizada por um aumento rápido e maciço da área foliar e determina o fim da dependência da planta do tubérculo-semente. As plantas atingem a autossuficiência (fase autotrófica), aproximadamente, seis semanas após surgimento da primeira folha. O desenvolvimento foliar é acompanhado pelo alongamento dos caules, aumento no número de ramos, completando a ramificação num período que varia de 120 a 150 dias, após plantio. Nesta fase também ocorre o crescimento do sistema radicular da planta e a decomposição do tubérculo-semente. No final da fase vegetativa, a planta tende a acumular carboidratos em excesso e estes acionam o início da tuberização com a decomposição total do tubérculo e o aparecimento do órgão de reserva que aparece em forma globosa, pequeno, com coloração clara em formas de dedos (Fig. 4), ligado ao caule aéreo rodeado por raízes, esta fase se encerra com o começo do florescimento, quando a planta atinge seu tamanho máximo. O tubérculo-semente fornece os nutrientes essenciais ao desenvolvimento da planta, após a brotação, terminando a função alimentadora, a partir do aparecimento dos ramos primários e do aumento da área foliar e do órgão de reserva, o qual originará os novos tubérculos.

\section{c) Fase reprodutiva}

Inicia a partir de seis meses após o plantio, com o aparecimento das flores e tubérculos em desenvolvimento e termina com o secamento das ramas aos sete meses. Os agricultores da comunidade da Maloca colhem o cará com 


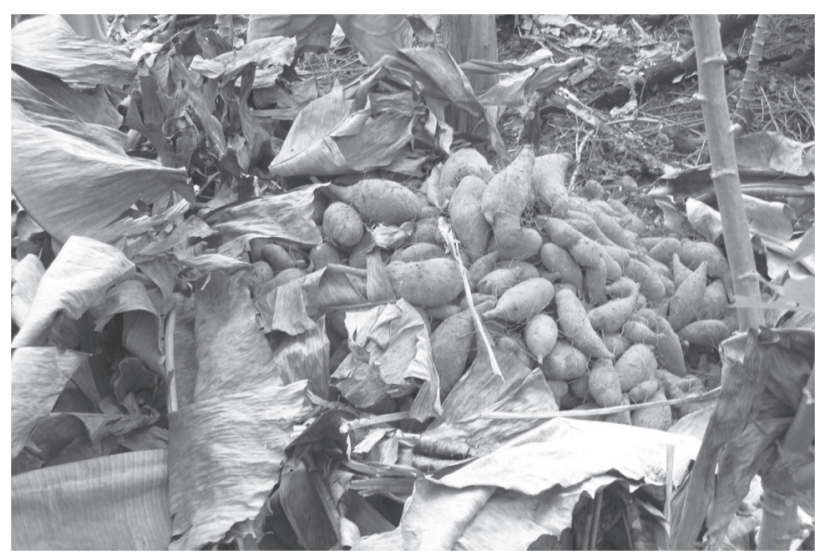

Figura 2. Forma de armazenamento dos tubérculos-sementes nas áreas de produção dos agricultores familiares de Caapiranga, estado do Amazonas, 2010.

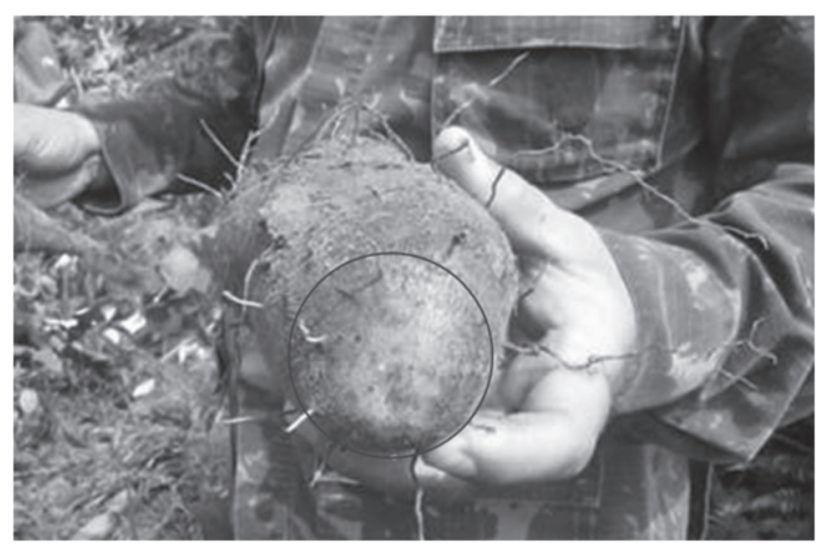

Figura 3. Agricultor mostrando área distal de cor clara (círculo) revelando que o cará de sete meses, após plantio ainda está verde para plantio, fase de dormência, 2010.

Tabela 1. Observações das fenofases de desenvolvimento do cará (Dioscorea trifida L.f.) a partir do etnoconhecimento dos agricultores do município de Caapiranga, estado do Amazonas, 2010-2011.

\begin{tabular}{lc}
\hline Fases de desenvolvimento do cará & $\begin{array}{c}\text { Tempo/dias } \\
\text { após plantio }\end{array}$ \\
\hline Dormência (Brotação) & 40 a 80 \\
Primeiras folhas & 80 a 90 \\
Ramos primários & 90 a 120 \\
Ramos secundários & 120 a 150 \\
Tuberização (aparecimento do órgão de reserva) & 120 a 270 \\
Floração & 180 a 210 \\
Seca das ramas & 210 a 270 \\
Colheita & 210 a 360 \\
\hline
\end{tabular}

sete meses de idade, época de aparecimento de algumas folhas com coloração amarela e flores com coloração cor de palha seca amarelada. De acordo com os dados, o cará colhido aos sete meses revela um tamanho bom para comercialização e maior vida útil de prateleira, porém não é bom para semente, quando comparado aos colhidos a partir de nove meses, após plantio.

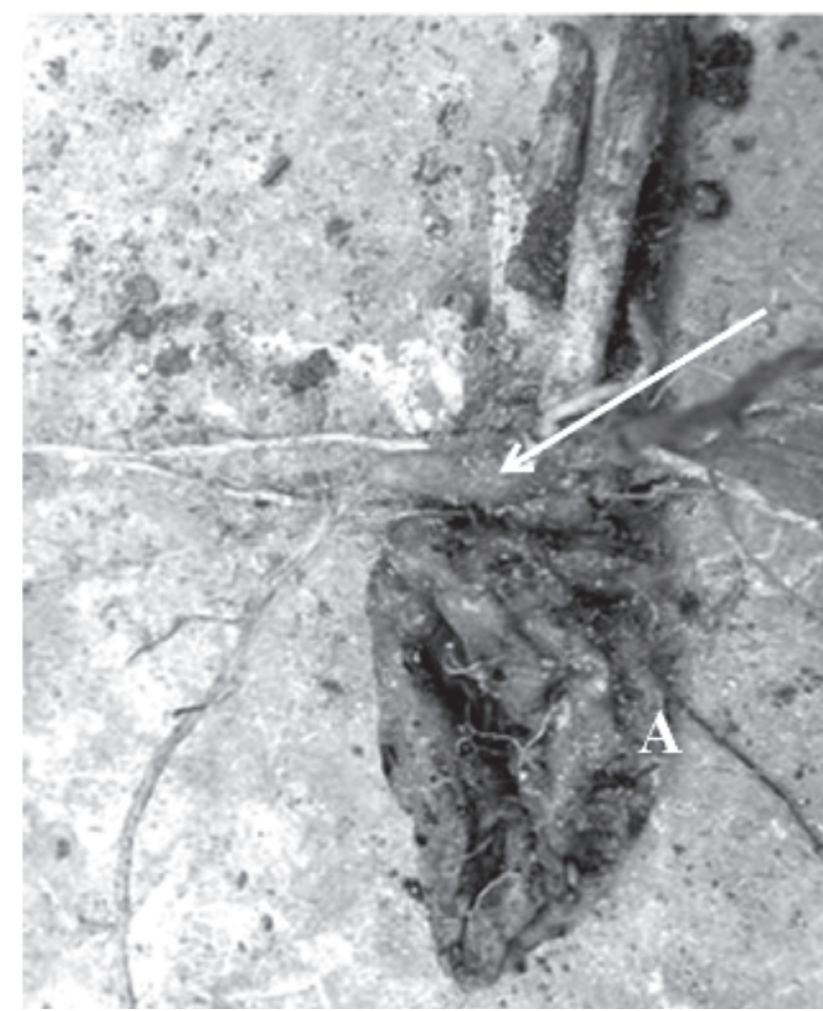

Figura 4. Planta de cará com tubérculo-semente em decomposição (A) e formação do órgão de reserva (seta branca). 2010.

d) Fase de secamento da planta ou maturação

É caracterizada pela morte da parte aérea da planta, com secagem e perda das folhas e ramos. Ocorre a partir do $7^{\circ}$ mês, após o plantio, sendo severa no $9^{\circ}$ mês. Embora a época de colheita seja em conformidade com $85 \%$ dos agricultores, aos nove meses de idade, $15 \%$ dos agricultores da orla do lago de Caapiranga colhem o cará no $7^{\circ}$ mês. Todas as fases de desenvolvimento com seu respectivo tempo, estão na tabela 1 .

\section{Agrodiversidade de cará (Dioscorea spp.) no município de Caapiranga.}

A identificação botânica dos carás produzidos em Caapiranga revelou que a principal espécie cultivada pelos agricultores (100\%) é a Dioscorea trifida L.f., embora entre estes agricultores também houvesse alguns (12\%) que cultivassem outras espécies, como a D. bulbifera L. Dioscorea trifida é uma planta trepadeira de caule volumoso e fino, que se enrola para a esquerda no sentido anti-horário, e que tem duas ou mais alas membranosas, geralmente em maior número na parte inferior do caule. Possui folhas pecioladas (pecíolos angulosos, que variam até $15 \mathrm{~cm}$ de comprimento), alternas, às vezes opostas com três a cinco lobos de forma acuminados ou oval-agudos (Fig. 5A), forma e tamanhos diversos, mais ou menos pilosas nas duas faces. As plantas são dioicas, com flores masculinas dispostas em racemos, formando uma inflorescência estaminada. As flores femi- 
ninas com ovários densamente híspidos formam inflorescência. Nos ramos, surgem dois cachos simples da mesma axila formam uma inflorescência de coloração esverdeada de 4 a 6 mm de diâmetro (Fig. 5B). As inflorescências dão origem a infrutescências aladas, com fruto em forma de cápsula com três lobos, cada um, com duas sementes de, aproximadamente $27 \mathrm{~mm}$ de comprimento e $17 \mathrm{~mm}$ de diâmetro (Fig. 5C), contendo sementes orbiculares (Fig. 5D) (Corrêa 1978; Caúper 2006).

Dioscorea trifida possui tubérculos subterrâneos com forma ovoides, cilíndricos, arredondados ou diversificados que variam entre 10 a mais de $30 \mathrm{~cm}$ de comprimento, e com massas frescas entre 50 a 4.500 g e coloração da polpa roxa, branca ou amarela. Características essas que os colocam em categoria e classificações diferentes a partir da percepção local dos agricultores (Fig. 6A, B, C, D, E, F).

As roças dos agricultores familiares de Caapiranga possuem, segundo o levantamento etnobotânico, uma elevada diversidade interespecífica de cará. A partir da análise participativa de quatro-células, verificou-se, que há 15 variedades locais conhecidas e 11 cultivadas. Destacou-se a variedade cará-roxo-comum como a mais cultivada, em área, por todos os agricultores (100\%), seguido do cará-branco (67\%) em grandes áreas por poucas famílias (Fig. 6). As variedades com frequências intermediárias: cará-pata-de-onça (17\%), cará-roxão (7\%), cará-inhame (3\%) e cará-rabo-de-mucura (3\%) são cultivados em pequenas áreas por muitas famílias, apenas para subsistência (Fig. 6). Alguns agricultores colocam o cará-pata-de-onça e o cará-roxão, junto com o cará-roxo-comum, para comercialização. As variedades locais cará-durão (10\%), cará-macaxeira (7\%), cará-ovo-de-cavalo (7\%), cará-miguel (3\%) são as menos cultivadas, indicando risco de perda da diversidade destas variedades nestas roças (Fig. 7). Acredita-se que isto ocorra por estas variedades não serem utilizadas para comercialização, perdendo espaços em área cultivada para o cará-roxo-comum e cará-branco. Rana e Sthapit (2007) relatam que variedades locais cultivadas por poucas famílias, em pequenas ou em grandes áreas, são vulneráveis à erosão genética, tornando-se necessárias intervenções, tais como: melhoramento de plantas, adição de valor, formação de coleções de variedades locais nas comunidades rurais, reconhecimento e vinculação com o mercado para geração de renda, para garantir a continuidade de sua manutenção nas unidades produtivas dos agricultores familiares. Salienta-se também a importância de bancos de germoplasma ex situ e unidades de observação e/ou demonstração para conservação, produção de propágulos e intercâmbio destas variedades sob risco de erosão genética.

Os nomes dados pelos agricultores de Caapiranga às variedades locais têm uma particularidade diferente e estão relacionados às características do tubérculo, comparado através da percepção local: a vegetal, animal, a ações entre outros fatores ligados ao universo cultural destes agricultores, por exemplo, o cará-pata-de-onça é comparado com a pata de uma onça; o cará-miguel é denominado, desta forma, pois um agricultor, chamado Miguel, foi o primeiro a plantar e a disseminar esta variedade; assim como, o cará-alemão, cultivado e disseminado, por um agricultor, conhecido pelo apelido de Alemão.

Para Albuquerque (2008), os seres humanos sentem uma imensa necessidade de classificação para ordenar as coisas, objetos, animais e plantas, enfim, o ambiente que o cerca, categorizando-o, nomeando-o de modo a não se perder na complexidade. Relata ainda, que em todas as culturas, os seres humanos desenvolvem estratégias que lhes asseguram a organização e classificação do mundo vegetal, nomeando também, de forma inclusa dentro de uma hierarquia etnobotânica descritiva, onde presta especial atenção à classificação do mundo vegetal, empregando uma abordagem linguística e antropológica. Essa abordagem pode ser coletivamente denominada de etnotaxonomia,

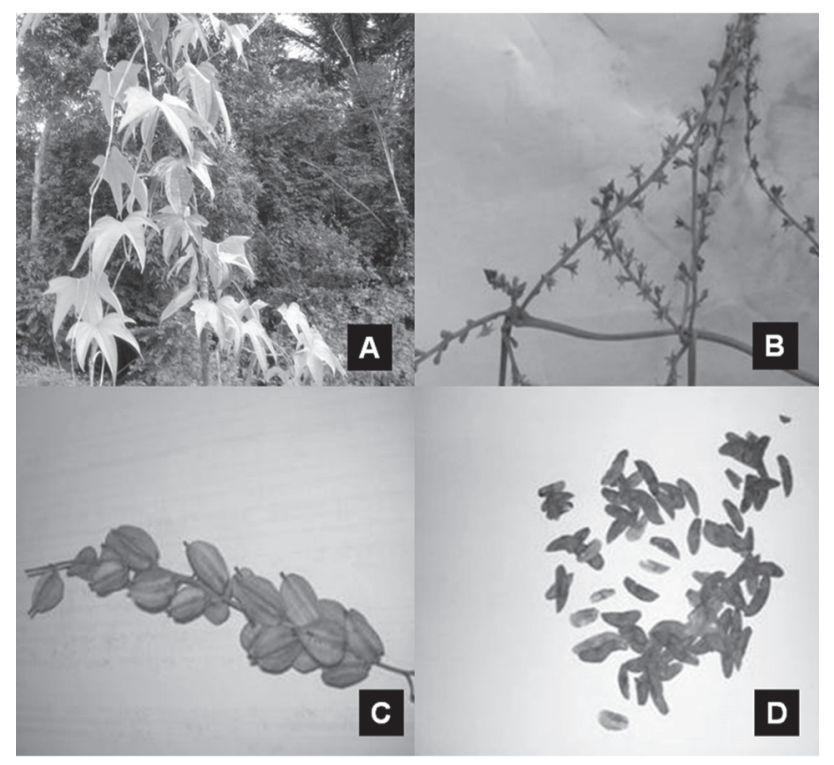

Figura 5. Planta Dioscorea trifida L.f. com caule glabro desenvolvendo-se para a esquerda no sentido anti-horário com folhas pentalobada (A). Possui inflorescência (B) e infrutescência com fruto em cápsula oblonga, pubescente (C) contendo sementes orbiculares e aladas (D).

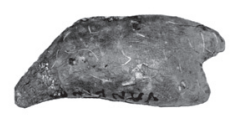

A

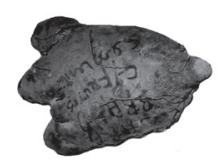

D

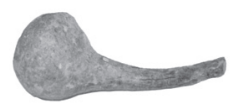

B

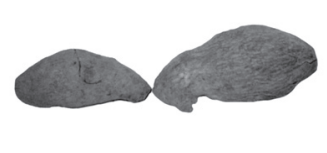

E
C

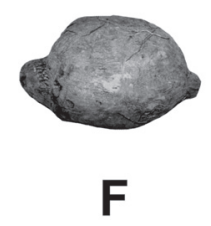

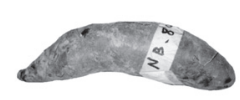

Figura 6. Variedades locais: cará-branco (A), cará-ovo-de-cavalo (B), cará-macaxeira (C), cará-pata-de-onça (D), cará-roxão (E) e cará-durão (F) cultivados nas roças dos agricultores de Caapiranga/AM. 


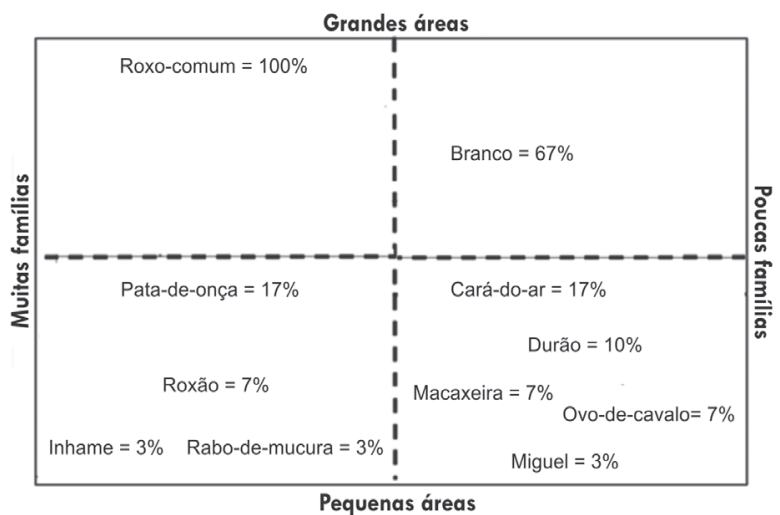

Figura 7. Análise participativa de quatro-células da abundância e distribuição da diversidade de espécies e variedades de cará nas comunidades produtoras de Caapiranga, estado do Amazonas, 2011.

onde são registradas as categorias nominadas que revelam um sistema de classificação subordinando categorias de realidade, hierarquicamente ordenadas.

Denominando as variedades pelos agricultores, os nomes dados são generalizados e compartilhados no cotidiano e repassados através de gerações fora ou dentro das comunidades rurais amazônicas, como por exemplo, o cará-pata-de-onça conhecido por esta denominação na comunidade Maloca, também e conhecido com este nome em Vila Nova. Albuquerque (2008) relata que o mundo biológico é denominado em função da percepção dos seres humanos sobre as características, sejam elas intrínsecas (substâncias produzidas que, por exemplo, emitem odores típicos) ou extrínsecas (morfologia) e as denominações podem levar em consideração atributos morfológicos e simbólicos.

A pesquisa através dos elementos êmicos, sobre a agrodiversidade de cará nas roças, permitiu compreender a visão local sobre a noção das etnovariedades no mundo real e imaginário dos agricultores, esta visão está atribuída ao cotidiano e a vivencia dos agricultores. É importante ressaltar que todos os nomes atribuídos às variedades têm determinada história, e que o nome usado em uma variedade, na comunidade Patauá ou na Maloca, ou em qualquer local do Baixo Solimões, é o mesmo. Nesse sentido a transição de material genético entre os agricultores não se dá apenas na difusão deste, mas na identidade de cada variedade em cada cultura.

\section{Características das variedades locais}

A identificação botânica revelou que as variedades locais cará-roxo-comum, cará-branco, cará-roxão, cará-durão, cará-macaxeira, cará-pata-de-onça, cará-ovo-de-cavalo, cará-rabo-de-mucura, cará-miguel, cará-inhame, pertencem à espécie Dioscorea trifida L.f. Todas as etnovariedades locais citadas possuem folhas pentalobadas, com coloração abaxial, verde-claro e adaxial, verde-escuro, pecíolo com tamanhos variados e caule do tipo alado quadrangular (Tab. 2). Seus tubérculos possuem epiderme marrom-escura com poucas raízes, forma variada, polpa com coloração roxa e branca homogênea destaque para última, sendo apenas o cará-roxo-comum, cará-roxão, cará-durão de cor roxa. Vale ressaltar que as etnovariedades cará-miguel e cará-inhame possuem coloração roxa muito escura, que quando em forma de suco fica parecido com a bebida de açaí (Euterpe spp.). Em relação ao tamanho e peso dos tubérculos as variedades que se destacam são cará-pata-de-onça, cará-macaxeira que variam de 300 a mais de $500 \mathrm{~g}$ (Tab. 2). Embora todas as etnovariedades pertençam a espécies $D$. trifida, possuem características como a forma, coloração, sabor e tamanho que aos diferenciam e levam os agricultores a denominá-las conforme sua percepção, é possível que estas características diferentes sejam devido ao cruzamento que ocorrre entre as plantas nas roças. Entretanto, não há estudos sobre tal hipótese. Os descritores morfológicos revelaram que o cará-do-ar ( $D$. bulbifera) foi o único que se manteve mais afastado das demais variedades por ser uma espécie diferente das demais, possui folhas inteiras, cordiformes e apresenta tubérculos aéreos e o fruto é uma cápsula oblonga, com lóculo contendo duas sementes aladas, na parte inferior (Tab. 2).

Outras variedades locais citadas pelos agricultores, no entanto não mais cultivadas, foram: cará-alemão, cará-creme, cará-espinho e cará-sucuriju. Embora muitos conheçam várias espécies e/ou variedades, poucos são os que as têm em suas roças o que mostra a Fig. 8. Nota-se que a variedade local, roxo-comum, está ganhando espaços em área plantada de outras variedades por ser a mais comercializada. A partir deste contexto, pode-se inferir que as roças de cará, em Caapiranga, possuem uma razoável diversidade de variedades locais. Contudo, se pôde constatar que as condições que levaram à criação e conservação desta agrodiversidade estão se modificando, ou seja, as roças ao longo do tempo foram sofrendo perda de diversidade de cará. Observou-se que tal problema pode estar relacionado à preferência dos agricultores pelas variedades de maior valor comercial e pela influência dos hábitos alimentares por apenas algumas variedades, como por exemplo, as entrevistas revelaram que $65 \%$ dos agricultores preferem mais o cará-roxo-comum devido ao seu sabor e a coloração e sabor que dá a carne ou ao peixe quando preparados com este tubérculo. Emperaire (2002) relata que, atualmente, a diversidade agrícola tradicional não responde mais às expectativas dos agricultores, cujas estratégias tradicionais de sobrevivência devem combinar objetivos de autonomia alimentar, com objetivos de inserção no mercado, causando, desta forma, automaticamente, uma redução na diversidade agrícola, ou seja, quando os agricultores priorizam mais o cará-roxo reduzem a área agrícola para as outras variedades.

Neste sentido, são necessários mais trabalhos técnico-científicos e de extensão, bem como, expedições de coleta de germoplasma para cultivos ex situ. Estudos etnobotânicos também são necessários para resgatar os conhecimentos 
Tabela 2. Descritores morfológicos das variedades e/ou espécies de cará (Dioscorea spp.) das comunidades produtoras de Caapiranga, estado do Amazonas.

\begin{tabular}{|c|c|c|c|c|c|c|c|c|c|}
\hline \multirow{2}{*}{ Variedades } & \multicolumn{2}{|c|}{ Folha } & \multicolumn{2}{|c|}{ Haste } & \multicolumn{5}{|c|}{ Tubérculo } \\
\hline & $\mathrm{CF}$ & FF & $\mathrm{CH}$ & $\mathrm{FH}$ & PTA & PRT & FT & CMT & PMT \\
\hline Cará-branco & 1 & 2 & 1 & 2 & 2 & 1 & 4 & 3 & 3 \\
\hline Cará-roxo & 1 & 2 & 1 & 2 & 2 & 1 & 3 & 2 & 3 \\
\hline Cará-roxão & 1 & 2 & 1 & 2 & 2 & 1 & 3 & 1 & 1 \\
\hline Cará-pata-de-onça & 1 & 2 & 1 & 2 & 2 & 1 & 4 & 3 & 3 \\
\hline Cará-ovo-de- cavalo & 1 & 2 & 1 & 2 & 2 & 2 & 3 & 1 & 1 \\
\hline Cará-inhame & 1 & 2 & 1 & 2 & 2 & 2 & 1 & 2 & 2 \\
\hline Cará-rabo-de-mucura & 1 & 2 & 1 & 2 & 2 & 1 & 1 & 2 & 2 \\
\hline Cará-macaxeira & 1 & 2 & 1 & 2 & 2 & 1 & 1 & 3 & 3 \\
\hline Cará-durão & 1 & 2 & 1 & 2 & 2 & 1 & 1 & 2 & 2 \\
\hline Cará-do-ar & 1 & 3 & 1 & 1 & 1 & 2 & 2 & 1 & 1 \\
\hline Cará-miguel & 1 & 2 & 1 & 2 & 2 & 1 & 3 & 1 & 1 \\
\hline
\end{tabular}

CF-cor da folha: 1- verde-claro, 2-verde-escuros; FF- forma da folha: 1- sagitada, 2- lobada; 3- cordiforme; CH-cor da haste: 1- verde; 2-verde-arroxeada; FHforma da haste: 1- cilíndrica, 2- quadrangular, PTA-presença de tubérculo aéreo: 1-presente, 2-ausente; FT-forma do tubérculo: 1-cilíndrica, 2-esférica, 3- oval, 4-variada; PRT- presença de raiz nos tubérculos: 1- presença, 2-ausência; PMT- Peso em média dos tubérculos: 1- 100 a 300g, 2-100 a 500, 3- 300 a mais de 500; CMT-comprimento em média dos tubérculos: $1-8$ a $15 \mathrm{~cm}, 2-10$ a $20 \mathrm{~cm}, 3-15$ a mais de $30 \mathrm{~cm}$.

populares na forma de produção, manejo, usos múltiplos destas culturas, bem como, estimular que as populações tradicionais (e as urbanas) continuem a valorizar os alimentos regionais. Os valores alimentícios dos produtos locais também precisam ser mais bem pesquisados e divulgados de forma a fornecer aportes para minimizar a erosão genética nas roças dos agricultores tradicionais.

\section{Origem da variabilidade fenotípica das etnovariedades cultivadas}

Quando questionados sobre a origem da variabilidade fenotípica das variedades cultivadas, $25 \%$ dos agricultores pesquisados responderam que em áreas cultivadas somente com a variedade de cará-roxo é comum que na colheita sejam obtidas plantas com entrecasca roxa e polpa branca, com textura da polpa mais solta ou com uma polpa roxa, muito clara quase branca. Outros responderam que observaram o surgimento de plantas com as características da variedade de cará-branco mesmo onde tenham plantado apenas tubérculos-semente da variedade cará-roxo. Entretanto, 54\% dos agricultores responderam que não verificaram o surgimento de plantas com características distintas e $21 \%$ não souberam responder.

A variabilidade fenotípica entre as variedades pode estar associada à seleção natural ou produzida (artificial), variações ambientais (plasticidade fenotípica) ou com a própria segregação gênica na população (reprodução sexuada) (Tostain et al. 2007). Somente através de estudos com marcadores genéticos seria possível explicar a origem das variações intraespecíficas nas variedades locais de carás. Siqueira e Veasey (2009) relatam que Lebote et al. (1998) usando marcadores isoenzimáticos na espécie Dioscorea alata, identificaram que muitas exibiam variações diversas devido ao processo de seleção humana e às recombinações genéticas. Embora os agricultores tenham afirmado que não utilizam sementes-botânicas de cará para o plantio, será necessário averiguar se nas roças são produzidas sementes híbridas pelo cruzamento natural entre plantas que sendo viáveis poderiam dar origem a plantas com características distintas das variedades inicialmente cultivadas.

O aparecimento de plantas de cará-branco em áreas semeadas com cará-roxo, ou vice-versa, poderia ainda ser explicado pela prática de reutilização das áreas de plantio por dois ou mais anos. Esta prática pode possibilitar a regeneração de plantas, anteriormente cultivadas, pela presença no solo, de algumas partes vegetativas como, por exemplo, tubérculos, partes de tubérculos ou mesmo sementes remanescentes de ciclos de cultivo anteriores que possibilitariam o surgimento de plantas diferentes das que foram plantadas posteriormente. Embora os agricultores revelassem não utilizar sementes de cará para o plantio, acredita-se ter ocorrido o cruzamento entre plantas e o surgimento de novas variedades. No entanto, estudos sobre a biologia reprodutiva e a viabilidade de sementes de cará em condições controladas e em campo são necessários para verificação dessas hipóteses.

\section{Conservação da diversidade de cará em roças de agricultores tradicionais}

Embora o contexto anterior revele a perda de diversidade de variedade, ainda, pode-se constatar entre os agricultores pesquisados, a circulação de tubérculos-sementes, pelo menos das demais variedades (Fig. 7), pouco ou não comercializadas. Este intercâmbio tem papel fundamental no interior dessas comunidades produtoras de cará, pois servem como estratégia de conservação e difusão do germoplasma das variedades locais. Pode se inferir que as estratégias de conservação realizadas pelos agricultores tradicionais pesquisados, envolvam cinco pontos importantes: o conhecimento tradicional, os ecótipos (capoeira, floresta e roça), a diversidade de variedade, as relações 


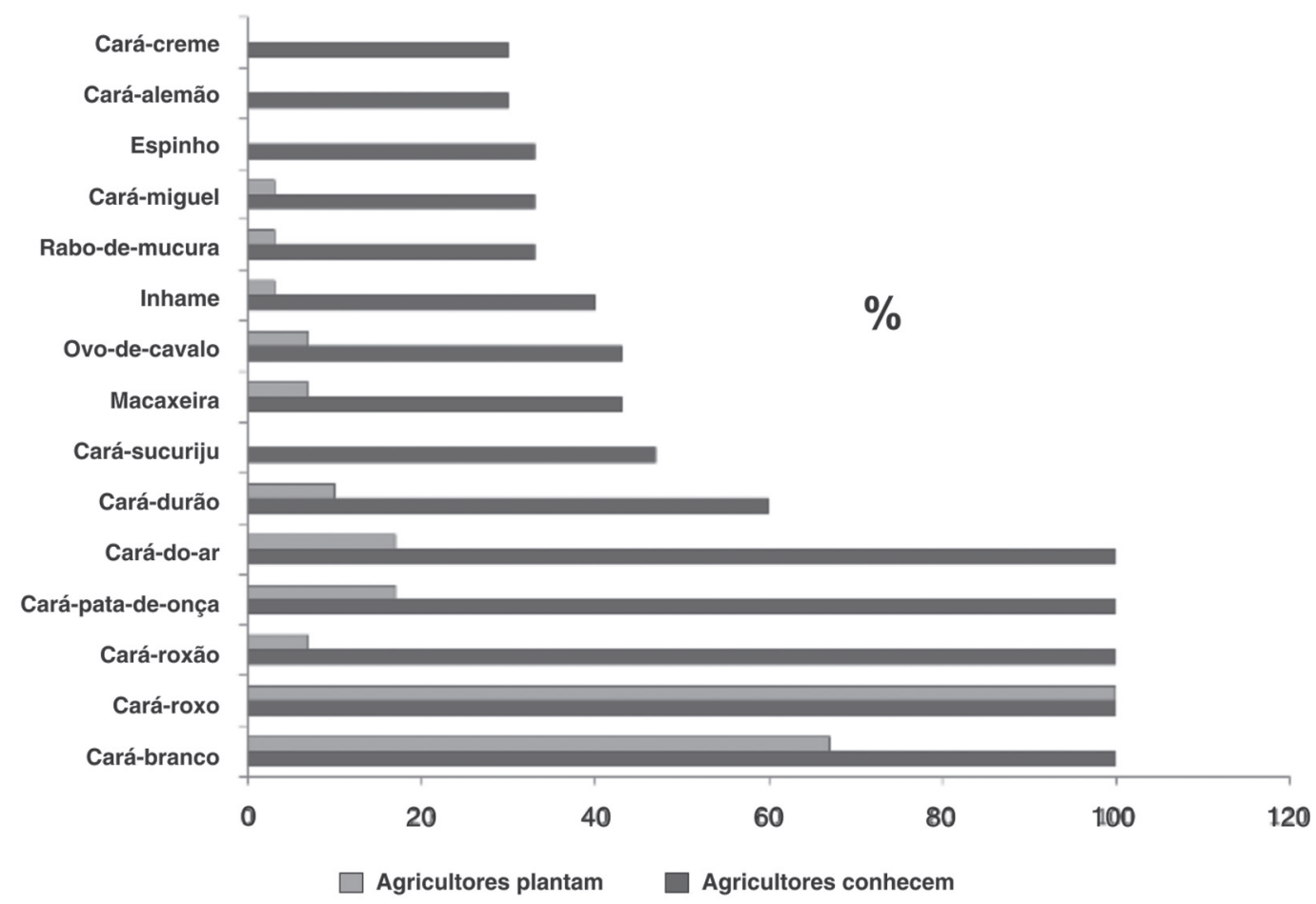

Figura 8. Freqüência dos agricultores que conhecem e cultivam variedades locais de cará (Dioscorea spp.) nas comunidades produtoras de Caapiranga, estado do Amazonas, 2009-2010.

sociais de circularidade das variedades e os múltiplos usos das variedades. As roças pesquisadas possuem características locais adequadas para pesquisa com diversidades de variedade interespecífica relacionadas ao cultivo do cará, podendo este, ser consorciado ou não com outras culturas. Com relação à manutenção da agrodiversidade pelos agricultores, $60 \%$ mantém as variedades locais como alternativas de consumo, $30 \%$ para ter opções de venda e troca e, $10 \%$ conservam por sua ação medicinal, como por exemplo, a variedade cará-roxão que é utilizado como depurativo e antianêmico. Ramos-Escudero et al. (2010, p.745-752) relatam que além de seu interesse nutricional, várias propriedades funcionais têm sido relatadas para os tubérculos de Dioscorea. Os tubérculos de cará têm apresentados significativas atividades antioxidantes contra os radicais livres, anti-hipertensivas, antitumoral e anti-inflamatório. Trabalhos realizados por estes autores detectaram doze pigmentos antociânicos em tubérculos fortemente coloridos de D. trifida, corriqueiramente consumidos pelos povos da floresta peruana.

O sentido de variedade local revela diversos níveis de homogeneidade biológica relativa à cultura. Dados coletados nas feiras revelaram que o cará é conhecido como roxo ou branco pelos consumidores, enquanto que nas roças, os agricultores reconhecem diversas variedades. As variedades que possuem aparência e sabor semelhantes são classificadas, nomeadas e agrupadas em diversos tipos. A denominação de cada variedade local se dá de acordo com a percepção do agricultor sobre a planta ou parte da planta como, por exemplo, o tubérculo.

Como foi dito anteriormente as variedades que se destacam em quantidade nas roças dos agricultores pesquisados são as direcionadas para comercialização como o cará-roxo-comum, cultivado por $100 \%$ dos agricultores e o branco por $67 \%$. Nesse sentido verifica-se que há variedades em risco, principalmente as que não são utilizadas para comercialização. Pode-se inferir que a diversidade agrícola quando não responde a expectativa do agricultor, pode ser reduzida. Nesse sentido, é necessária a condução de pesquisas e ações que visem combinar conservação das espécies, autonomia alimentar e inserção no mercado dos agricultores tradicionais. Tais ações devem ser precedidas de estudos sobre a variabilidade genética nas roças de cará e sobre o etnoconhecimento dos agricultores tradicionais. Além disso, a criação de bancos comunitários das variedades locais seria fundamental para a conservação in situ/ on farm e para estudos de diversidade genética e evolução. Acredita-se que, a partir dessa perspectiva, possam ser criados programas de conservação efetivos em nível local e regional para cultura do cará.

\section{Agradecimentos}

Ao consórcio CAPES e FAPEAM pela concessão da bolsa de doutorado à primeira autora e ao $\mathrm{MDA} / \mathrm{CNPq}$ pelo apoio financeiro desta pesquisa, através do projeto 
“Tecnologias sociais ecológicas: uma iniciativa para geração de trabalho, renda e fortalecimento da agricultura familiar nas comunidades rurais amazônicas", e aos agricultores e agricultoras de Caapiranga pela confiança, conhecimentos e experiências compartilhados e pelo carinho.

\section{Referências}

Abramo, M.A. 1990. Taioba, cará e inhame: o grande potencial inexplorado. Pp.65-80. São Paulo, Editora Ícone.

Albuquerque, U.P. 2008. Etnobotânica aplicada para a conservação da biodiversidade. Pp.227-240. In: Albuquerque, U.P.; Lucena, R.F.P. \& Cunha, L.V.F.G. (Orgs.). Métodos e técnicas na pesquisa etnobotânica. Recife, Comunigraf.

Cagnon, J.R.; Cereda, M.P. \& Pantarotto, S. 2002. Cultura de tuberosas amiláceas latino americanas. In Cd-rom. v. 2. Fundação Cargill.

Carvalho, P.C.L.; Teixeira, C.A. \& Borges, A.J. 2009. Diversidade genética em Dioscorea spp. no Recôncavo da Bahia. Revista Brasileira de Agroecologia 4(2): 515-519.

Caúper, G.B. 2006. Biodiversidade amazônica: flora amazônica. v.3. Manaus, Centro Cultural dos Povos da Amazônia-CCPA.

Corrêa, M.P. 1969. Dicionário das plantas úteis do Brasil e das exóticas cultivadas. v.4. Rio de Janeiro, Ministério da Agricultura/IBDF, Brasília,

Corrêa, M.P. 1978. Dicionário de plantas úteis do Brasil e das exóticas cultivadas. v.2. Rio de Janeiro, Instituto Brasileiro de Desenvolvimento Florestal.
Kirizawa, M.; Xifreda, C.C. \& Couto, R. 2012. Dioscoreaceae. In: Lista de espécies da flora do Brasil. Jardim Botânico do Rio de Janeiro. Disponível: <http://floradobrasil.jbrj.gov.br/2012/FB000104>. (Acesso em 12/01/2012).

Mabberley, D.J. 2008. Mabberley's Plant-book - A Portable Dictionary of Plants, their Classifications, and Uses. 3 ed. May, Cambridge University Press.

Montaldo, A. 1991.Cultivo de raices y tubérculos tropicales. San José, IICA.

Oliveira, A.P.; Barbosa, L.J.N; Pereira, W.E.; Silva, J.E.L.; Oliveira, A.N.P. 2007. Produção de túberas comerciais de inhame em função de doses de nitrogênio. Brasília. Horticultura Brasileira 25(1): 73-76.

Pedralli, G. 1998. O inhame, esse desconhecido. Ciência Hoje 8(46): 58-62,

Ramos-Escudero, F.; Santos-Buelga, C.; Pérez-Alonso, J.J.; Yáñez, J. A.; Dueñas, M. 2010. Identification of anthocyanins in Dioscorea trifida L.f. yam tubers (purple sachapapa). Eur Food Res Technol 230: 745-752.

Rana, R.B.; Sthapit, B. 2007. Análise Participativa de agrobiodiversidade de quatro-células. Pp. 160-177. Boef, S.W.; Thijssen, M.H.; Ogliari, J.B.; Sthapit, B.R. (Eds). In: Biodiversidade e agricultores: fortalecendo o manejo comunitário. v.1. Porto Alegre, LPM.

Santos, E.S. 2002. Manejo sustentável da cultura do inhame (Dioscorea sp.) no Nordeste do Brasil. Anais. v. I do II Simpósio Nacional sobre as Culturas do Inhame e do Taruo. João Pessoa-PB.

Siqueira, M. V. B. M.; VEASEY E. A. 2009. Raíces y tubérculos tropicales olvidados o subutilizados en Brasil. Revista Colombiana de Ciências Hortícolas 3: 110-125.

Tostain, S.; Agbangla, C.; Scarcelli, N.; Mariac, C.; Daïnou, O.; Berthaud, J. \& Pham, J. 2007. Genetic diversity analysis of yam cultivars (Dioscorea rotundata Poir.) in Benin using simple sequence repeat (SSR) markers. Plant Genetic Resources: Characterization and Utilization. 5(2): 71-81 